\title{
Analysis of the Work on International Students Coming to China and Countermeasures in the Post-epidemic Era
}

\author{
Yuan $\mathrm{He}^{1, *}$, Xueyi Yang ${ }^{1}$, Jia He ${ }^{1}$, Lei Lei ${ }^{1}$, Daohua Zhou ${ }^{2}$ and Jiang Hong ${ }^{2}$ \\ ${ }^{I}$ Chengdu University of Information \\ ${ }^{2}$ Chengdu Zhongke Daqi Software Co.,Ltd \\ *Corresponding author. Email: heyuan@cuit.edu.cn
}

\begin{abstract}
In the post-epidemic era, the education of international students coming to China is encountering significant challenges. Based on the current situation of international students studying in China, this paper aims to explore the problems that China is facing up and the corresponding countermeasures to find a way in promoting the development of the work on international students coming to China, which will help cultivate a group of international students who know, love and care about China, and then introduce the Chinese culture to the world.
\end{abstract}

Keywords: Education to the international students coming to China, COVID-19 pandemic, International students in China.

\section{INTRODUCTION}

Recently, the Central Conference on Talent Work was held. It was proposed that China enter a new era of talent innovation and implement the strategy of strengthening the country with talents. In contrast, talents cultivation should adhere to the dual policy of "going out" and "bringing in." Introducing skills and developing international education has become one of the essential strategic objectives of our country. Therefore, China must make great efforts to study abroad, build a first-class study abroad center and attract overseas students to study in China. However, the outbreak of COVID-19 in 2020 has had a severe impact on all fields in China and brought new challenges to studying in China. Taking adequate measures has become a significant issue for the education of learning in China in the post-epidemic era.

\section{ACHIEVEMENTS IN STUDYING IN CHINA}

\subsection{The Number of Students Studying in China is Increasing}

In 2010, the number of students studying in China was 260,000 , but by 2019 , the number of students studying in China had reached 514,900, and the personnel scale doubled. Due to the outbreak of the COVID-19 epidemic in 2020, the overseas students in China have changed. From the long-term development point of view, no statistics have been made. [1] At the same time, China has become a big country studying abroad. It is reported that China's international student market has reached $8 \%$, surpassing Germany and France and being second only to the United States and Britain, making it the third-largest international student destination in the world. As shown in figure 1.

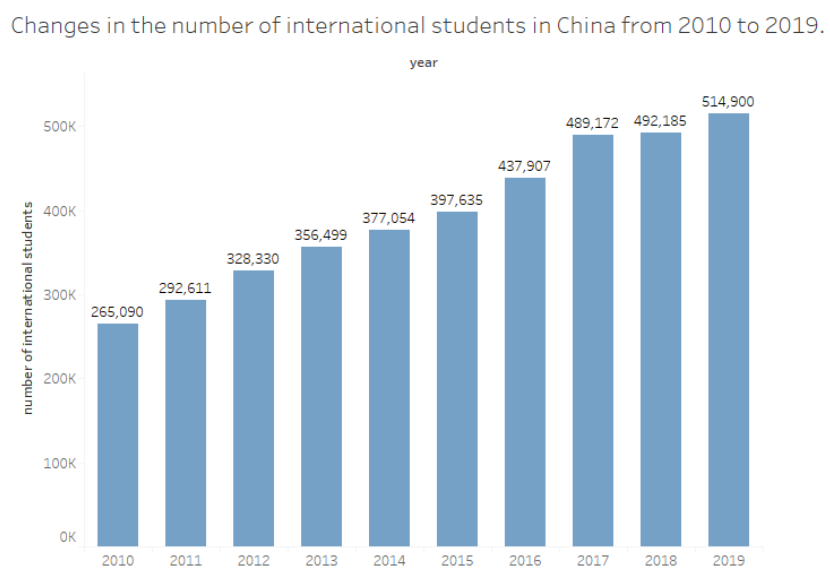

Figure 1 Scale chart of overseas students in China from 2010 to 2019. 


\subsection{The Structure of Overseas Students in China Has Been Continuously Optimized}

Shown and 2010, most of the overseas students in China mainly focused on non-academic education, short-term Chinese study, and further education, with the proportion as high as $60 \%$. In 2019 , according to the data released by the Ministry of Education, the balance of academic students of overseas students in China was as high as $54.6 \%$, which increased by $8.85 \%$ year-on-year in 2018, and the educational level of students was continuously optimized. [2].As shown in figure 2.

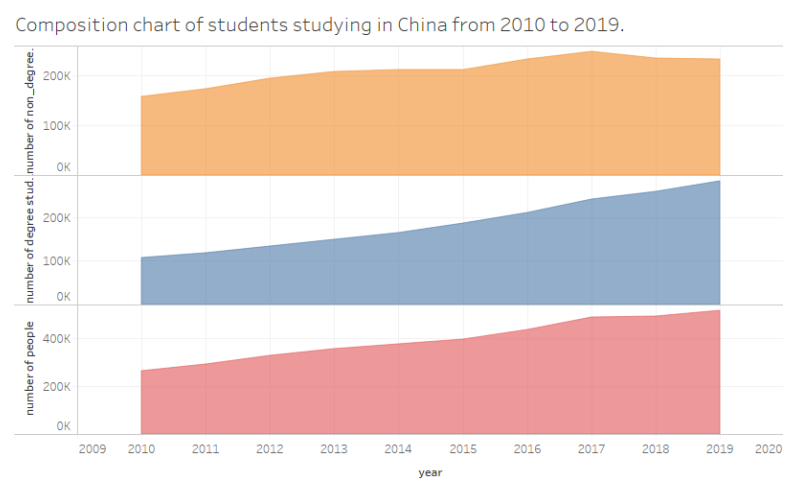

Figure 2 Growth trend of academic and non-academic students studying in China from 2010 to 2019.

\subsection{The Incentive System for Studying in China Has Been Constantly Optimized and The Incentive System Has Been Further Improved}

In 2016, the Ministry of Education issued the "Education Action Plan for Promoting the Coconstruction of" the belt and road initiative, "proposing contributing Chinese wisdom and sharing high-quality educational resources for world education and cultural exchanges as" messenger of civilized communication. "In 2019, "China Education Modernization 2035" clearly stated that "building an international study center" further clarified the policy goal of building a Chinese brand for studying abroad and achieved the policy goal through measures such as leading by values and calling for publicity. [3] international students are attracted to study in China by setting up scholarships at all levels. In 2019, 66,000 international students won scholarships provided by China, accounting for $12.83 \%$ of the total number of students studying in China. Apart from scholarships provided by the state, Chinese provinces, cities, universities, and significant enterprises also sponsored scholarships of different amounts and types for international students to study in China to encourage the vast number of international students to learn in China.

\section{PROBLEMS IN STUDYING IN CHINA}

\subsection{The International Environment Is Changeable, and Public Opinion Is Complicated}

Since COVID-19 was rampant, the world has been changeable. From the beginning, foreign attitudes towards China considered COVID-19 a slander of the "Chinese virus." They then fanned the flames of inappropriate remarks, which made China's diplomacy agitated and the international environment in a complex and changeable case. Therefore, in the postepidemic era, if the world wants to continue to develop, it must unite to fight the epidemic and form a community of destiny, to tide over the difficulties and usher in the recovery of the world economy and the peace of the world situation. Since China started to study in China, it has been giving students studying in China "special treatment," which has also attracted domestic attention. With the proper education now put forward, the special treatment for students studying in China is also at the forefront, pushing public opinion to a climax and attracting more attention. At the same time, to keep pace with internationalization, some colleges and universities have lowered the admission threshold for international students, neglected their abilities, not strictly controlled the quality of students, followed the principle of leniency in the management of international students, and were not standardized and too lenient in the application for scholarships, which also reflected the considerable problems in the work of studying in China and needed to be solved at a faster pace.

\subsection{Improvement of Internet Infrastructure Construction Department}

Under the influence of the COVID-19 epidemic, many students studying in China can't return to school, which seriously affects the students' learning progress. Therefore, most colleges and universities adopt online teaching. With the advent of the $5 \mathrm{G}$ era, the world has become more closely connected. Still, many colleges and universities have ancient infrastructure construction, which cannot meet the needs of students for synchronous video teaching on the global Internet. Replacing equipment and software requires a considerable workforce, material resources, and 
financial resources. Suppose the school funds are insufficient or the construction time is too long. In that case, this will significantly affect the class progress of international students, which will lead to many students failing to graduate on time, resulting in many students dropping out of school or dropping out of school.

\subsection{The Country of Origin, Professional Distribution Is Not Balanced}

According to the statistical data from the Ministry of Education of China from 2010 to 2019, the students who come to study in China mainly come from Asia, Africa, and other regions, mainly from neighbouring developing countries and areas such as South Korea, Thailand, and Pakistan. The proportion of personnel in developed countries is negligible. Thus, the study in China is not attractive to the personnel in developed countries. From the perspective of majors chosen by international students, most of the students studying in China choose liberal arts subjects such as management, literature, linguistics, etc. In contrast, the issues of science and engineering and medicine still have the problem of insufficient students. Therefore, the cause of studying in China needs to optimize the level of students further and broaden the choice of majors. See figure 3 and figure 4 .

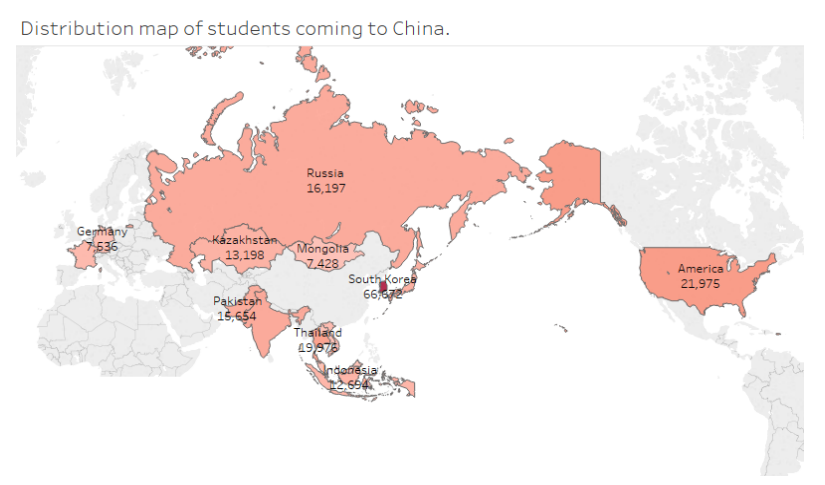

Figure 3 Distribution of students coming to china

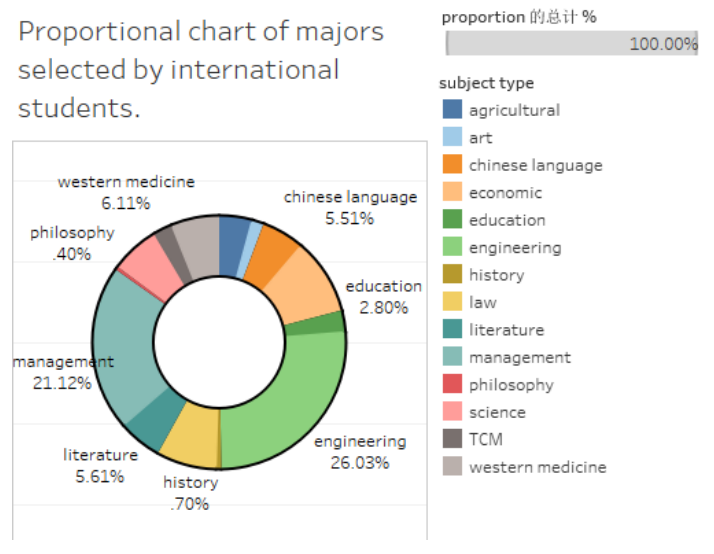

Figure 4 Scale chart of majors selected by international students.

\subsection{The Training Mechanism for International Students in China Is Not Perfect}

First of all, China's colleges and universities have the problem of lack of experience in carrying out the work of studying abroad. There are no clear written regulations on the mode of personnel training. There is no targeted and personalized training scheme for students studying in China, which seriously affects the satisfaction of overseas students studying in China. Secondly, because international students come from all parts of the world, their language level is inconsistent, so they have different understandings of the course content. However, the curriculum design for international students in China has not been treated differently, making international students quickly get tired of studying and lowering their expectations for studying abroad. Finally, there is no corresponding guidance and policy for the employment of students studying in China. Because of the above problems, to sum up, China does not have a standardized training mechanism for students studying in China, which makes it impossible for international students to finish their study abroad smoothly and apply what they have learned, thus causing them to encounter many problems in their study abroad career, which is also one of the problems that China needs to pay attention to.

\subsection{The Teaching Quality of International Students in China is not Guaranteed}

With the increase in the number of international students, there are severe problems in the quality of education in most universities in China. Only a few 
first-class universities can take classes in English, and their pronunciation is relatively standard, so international students can be barrier-free when attending classes and communicating. However, most colleges and universities lack talents, and many teachers can't teach in English. Some teachers can use English, but their pronunciation is not standard, with the heavy local accent, which also makes the learning quality of international students not high.

\subsection{The Management Methods of International Students in China Are Converging, and Problem Management Is Not Transparent}

Because there is no special management regulation for international students studying in China, the management method is the same as domestic students. However, due to the differences in customs and living habits of all parties, significant problems have arisen. When issues need to be solved, many departments are often involved and need to solve problems together. However, each department has no clear division of labor, and the responsible subjects are not precise, which leads to new problems instead of being solved.

\section{COPING STRATEGIES FOR OVERSEAS EDUCATION IN CHINA IN THE POST-EPIDEMIC ERA}

\subsection{Improve Laws and Regulations, And Complete the Management of Students Coming to China According to Laws and Regulations}

In the face of incorrect remarks globally, China should improve relevant laws and regulations and investigate the legal responsibilities of rumors and those who publish inappropriate comments to set an example to serve as a deterrent and avoid the bottomless smear of China by internet spots. At the same time, acting following laws and regulations, not exercising privileges for any one person, treating all students equally and without discrimination, strengthening the quality control of overseas students in China, and improving the relevant scholarship application system is more conducive to guiding public opinion and making China's education work develop relatively and healthily.

\subsection{Strengthen China's Hardware and Software Infrastructure Construction}

The software and hardware infrastructure of colleges and universities in China should be updated in time, and the state should actively respond and introduce related policies and standards, which standards can be replaced, and economic subsidies can be applied at the same time; Colleges and universities react to relevant situations promptly, make efforts to complete equipment upgrades promptly, so as not to delay essential work, and provide basic guarantee for online education for studying in China.

\subsection{Scientific Layout to Speed Up the Pace of International Cooperation in Running Schools}

Under the background of COVID-19 epidemic, facing the difficulties in studying in China, first of all, China should go ahead in many ways, strengthen publicity and attract high-quality students from all over the world; Then customize the enrollment policy; Finally, China should set up different incentives to stimulate high-quality students from all over the world to study in China. For example, we should encourage them from psychological factors for developed countries and regions instead of just staying on economic factors. At the same time, China should also launch activities such as co-constructing Confucius Institutes and friendly cooperative colleges, increasing overseas school-running institutions and projects of different types and levels, speeding up the pace of international cooperation in running schools, and bringing out cultures with Chinese characteristics and introduce international students. [4] Regarding subject preference, China should strengthen its running schools and focus on in-depth exploration in various fields so that international students can have more space in choosing majors.

\subsection{Innovate the Training Mode and Enhance the Diversity of Teaching Modes}

In terms of training mode, China should encourage innovation, set customized and personalized training modes for international students from different places of origin, and actively explore a new collaborative training mode oriented to the needs of enterprises so that international students can apply what they have learned and have the ability to work while studying, thus effectively solving the problem of international students' difficulty in finding a job. At the same time, the innovation of training mode will drive the creation 
of a teaching mode so that Chinese and international students can jointly improve through collaborative innovation. In the long run, It can not only solve the language problems of international students to varying degrees but also alleviate the problem of insufficient energy of instructors and achieve a balance between the training mode and the teaching mode, which is conducive to the stable and long-term development of the cause of studying in China.

\subsection{Strengthen the Construction of Teaching Staff and Improve the Quality Assurance System for Studying in China}

The level of teachers determines the quality of international students studying abroad. Only by improving the comprehensive quality of teachers, especially the international rate, can we prepare to enhance international students' grades. Among the international students' teaching staff in China, there are few people with global vision and intercultural communication ability. Therefore, China must constantly optimize its teaching structure. On the one hand, it can attract excellent foreign teachers to teach in schools through good policies; on the other hand, it should pay attention to the international training of domestic teachers so that they can have bilingual teaching ability. In addition to improving teachers' skills, we should also strengthen cooperation among teachers, increase collaboration among them, jointly train international students, and make up for their knowledge gaps in various fields, to improve the learning quality of international students in China and continuously output excellent talents for studying abroad.

\subsection{Innovate Management Methods and Build Collaborative Mechanisms}

Studying in China is a comprehensive event involving many fields closely related to school education and affects the areas of diplomacy, finance, ethnic religion, etc. Therefore, the management of overseas students should consider various problems and different factors from different angles. [2] At the same time, studying in China also involves countries, provinces, cities, and universities, so it is necessary to cooperate and manage together in many aspects of management. From a microscopic point of view, international students come from all over the world, with different customs and living and working habits, so it is necessary to establish differentiated management methods, which cannot be generalized.

\section{CONCLUSION}

This paper discusses the achievements, difficulties, and corresponding solutions of studying in China, hoping to provide some reference and thinking for looking in China. Facing the uncertain new situation in the world, the world has entered a new stage of development, and the country has proposed to establish new ideas, new patterns, new goals, and new requirements. Facing the challenges of the development of overseas education in China in the post-epidemic era, we should pay attention to the Research on the training strategy of overseas students, build a complete policy chain for overseas students, and enhance the fit between the training of overseas students in China and the development needs of the source countries and China. Strengthen standardized management, improve the quality of personnel training, promote the connotative development of studying in China, and build a brand school and a brand major of "studying in China." Strengthen the international recognition of Chinese culture, cultivate a group of faithful communicators of Chinese culture, and make Chinese culture better integrated into the world.

\section{AUTHORS' CONTRIBUTIONS}

XUEYI YANG is mainly responsible for collecting data, sorting out data and writing articles; YUANHE is mainly responsible for sorting out the structure of articles and guiding the production of pictures; JIAHE is mainly responsible for collecting documents; LEILEI is mainly responsible for checking data and writing.

\section{ACKNOWLEDGMENTS}

This research was supported by the project of CUIT for education \& teaching research and reform (JYJG2021117, JYJG2021117)

\section{REFERENCES}

[1] Yin Hao, Liu Haitian. The development challenges and countermeasures of studying China in the post-epidemic era _ yin Hao [J]. China geological education, 2021, 30(2): 10-14.

[2] Zuo Li, Zhou Di, Tan Huimin, et al. Research on the Influence of Post-epidemic Period on the Enrollment of Overseas Students in China and 
Countermeasures _ Zuo Li [J]. University Education, 2021(7): 164-166.

[3] Liu Haitian, Deng Yicong. The current situation and development trend of studying in China under the new case _ Liu Haitian [J]. Economist, 2021(7): 213-214.
[4] Zhang Wei. The development trend of global study abroad education and China as _ Zhang Wei [J]. Shandong Higher Education, 2021, 9(3): $15-22$. 